\title{
Contribuição das Internações por Condições Sensíveis à Atenção Primária nas internações hospitalares do estado do Maranhão entre 2010 e 2014
}

\section{Contribution of hospitalizations for conditions sensitive to primary care in hospital admissions in the state of Maranhão between 2010 and 2014}

DOI: $10.46919 / \operatorname{archv2n5-003~}$

Recebimento dos originais: 01/05/2021

Aceitação para publicação: 31/06/2021

\section{Maria Sabrina Medeiros Olímpio}

Graduação em Medicina pela Universidade Estadual Do Maranhão, UEMA, BRASIL.

Residente de Radiologia e Diagnóstico Por Imagem do Hospital Universitário da Universidade Federal Do Piauí, HU UFPI.

Instituição de atuação atual: Hospital Universitário da Universidade Federal Do Piauí - HU UFPI.

Endereço completo: Rua Miosotis, 1444, Fátima, Teresina - PI, CEP: 64048-130

E-mail: sabrinamolimpio@ hotmail.com

\section{Renata Silva do Nascimento}

Graduação em Medicina pela Universidade Estadual Do Maranhão, UEMA, BRASIL.

Residente de Radiologia e Diagnóstico Por Imagem do Hospital Israelita Albert Einstein.

Instituição de atuação atual: Hospital Israelita Albert Einstein, São Paulo.

Endereço completo: Hospital Israelita Albert Einstein, Avenida Padre Lebret, 801, Jardim Lenor, São

Paulo

E-mail: renatasn63@gmail.com

\section{Ana Priscila Medeiros Olímpio}

Mestrado em Biodiversidade, Ambiente e Saúde pela Universidade Estadual Do Maranhão, UEMA, BRASIL.

Doutorado em andamento em Genética e Biologia Molecular pela Universidade Federal do Pará, UFPA, Brasil.

Instituição de atuação atual: Universidade Federal do Pará

Endereço completo: Rua Santa Maria, 1547, Caxias - MA, CEP: 65602-840

E-mail: priscila_cx2006@hotmail.com

\section{INTRODUÇÃO}

A Atenção Primária a Saúde (APS), porta de entrada preferencial do sistema público de saúde, pode resolver até $90 \%$ dos casos que lhe são demandados. Logo, sua não efetividade aumenta a demanda nos demais níveis de atenção e afeta a resolutividade dos mesmos. Para avaliar a eficiência da APS, criou-se o indicador de Internações por condições Sensíveis à Atenção Primária (ICSAP), ou seja, internações evitáveis caso os serviços de atenção básica sejam efetivos e acessíveis. No Brasil, as ICSAP são listadas pelo Ministério da Saúde (MS) na Portaria $N^{\circ} 221$, de 17 de abril de 2008, em 19 grupos de causas de internações e 74 diagnósticos.

\section{OBJETIVO}


Identificar a contribuição das ICSAP entre o total de internações registradas no estado do Maranhão entre janeiro de 2010 e dezembro de 2014 quanto ao número dessas internações, custo financeiro e distribuição nos grupos de causas.

\section{METODOLOGIA}

Estudo descritivo retrospectivo realizado a partir de busca online no Sistema de Informação Hospitalar do DATASUS das ICSAP definidas pela Portaria $\mathrm{N}^{\circ} 221$ do Ministério da Saúde. Foram colhidos os seguintes dados: números absolutos de ICSAP (e sua distribuição por grupos de causas), custos financeiros das ICSAP (em conjunto e distribuição por grupo de causa), números absolutos e custos financeiros de internações no Estado do Maranhão no período considerado. Os dados foram organizados em planilhas e analisados no programa Microsoft Office Excel®. Para verificar a representatividade das ICSAP, foi calculado o valor percentual destas em relação ao total de internações, ano a ano. Para o detalhamento por grupos de causas, foram calculados os valores percentuais médios no período desses grupos entre as ICSAP.

\section{RESULTADOS}

Ao longo do período, as ICSAP representaram cada vez menos do total de internações (Gráficos 1 e 2) tanto em número de hospitalizações (37,6\% em 2010 para 34,7\% em 2014) quanto em custos financeiros (28,3\% dos custos de internações em 2010 foi por ICSAP, em 2014 passou a ser 24,4\%). Dentre os 19 grupos de causas, as Gastroenterites Infecciosas e Complicações, Pneumonias Bacterianas e as Infecções no Rim e Trato Urinário foram as mais significativas, representando, em média, 61,4\% de todas as ICSAP, enquanto as Doenças Preveníveis por Imunização, Anemia e Doenças Relacionadas ao Pré-Natal foram as menos representativas com apenas 0,8\% das ICSAP (Tabela 1). Angina, Insuficiência Cardíaca e Doenças Cerebrovasculares tiveram, juntas, os custos financeiros mais altos, representando, em média, 45\% dos custos por internação entre as ICSAP.

\section{CONCLUSÃO}

Apesar da redução na contribuição das ICSAP para o total de internações no Maranhão entre 2010 e 2014, os números ainda são significativos. Por isso, é necessário continuar o fortalecimento da Estratégia de Saúde da Família e da APS, com ênfase à detecção e tratamento precoce de Gastroenterites Infecciosas, Pneumonias Bacterianas e Infecções do Trato Urinário, por corresponderem aos maiores números entre as ICSAP, bem como identificação e manejo adequado das condições que predispõem à Angina, Insuficiência Cardíaca e Doenças Cerebrovasculares, já que essas condições representam os maiores custos financeiros das ICSAP. 
Palavras-chaves: Atenção Primária à Saúde. Estratégia de Saúde da Família. Indicadores de Saúde Pública. Avaliação de Serviços de Saúde. Perfil de Internações Hospitalares.

Gráfico 1 - Contribuição das ICSAP nas internações do estado do Maranhão, 2010 - 2014, quanto a números de internações.

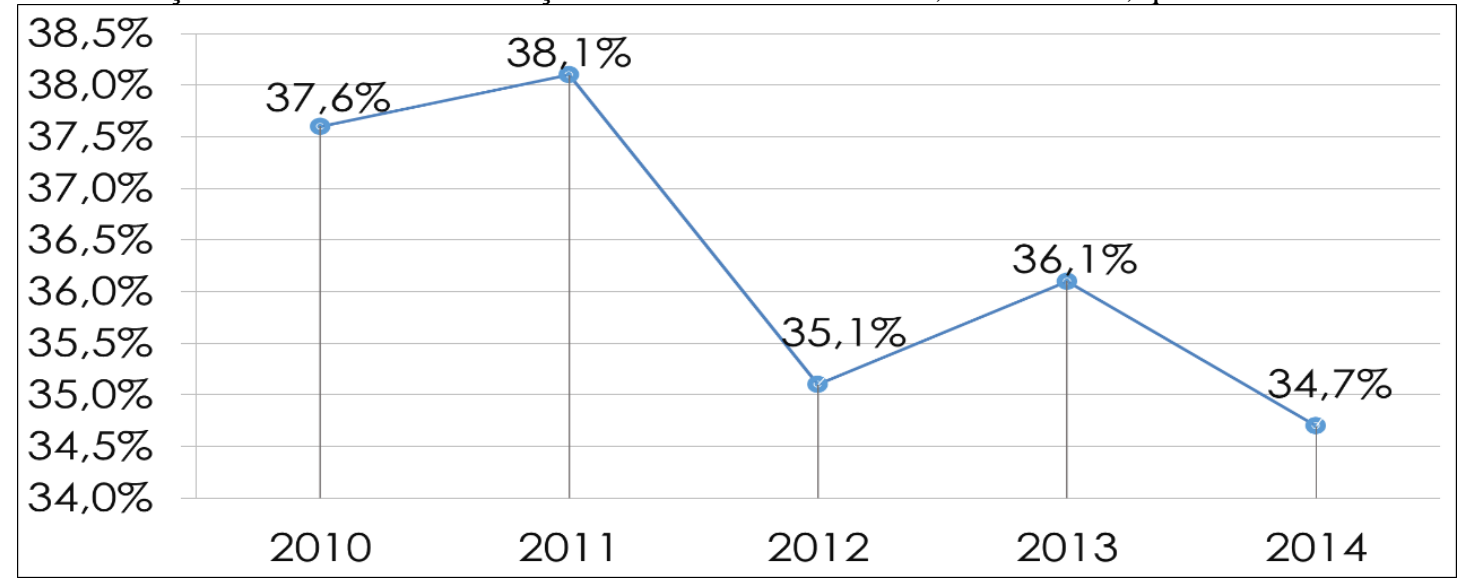

Fonte: Autores

Gráfico 2 - Contribuição das ICSAP nas internações no estado do Maranhão, 2010 - 2014, quanto a custos financeiros.

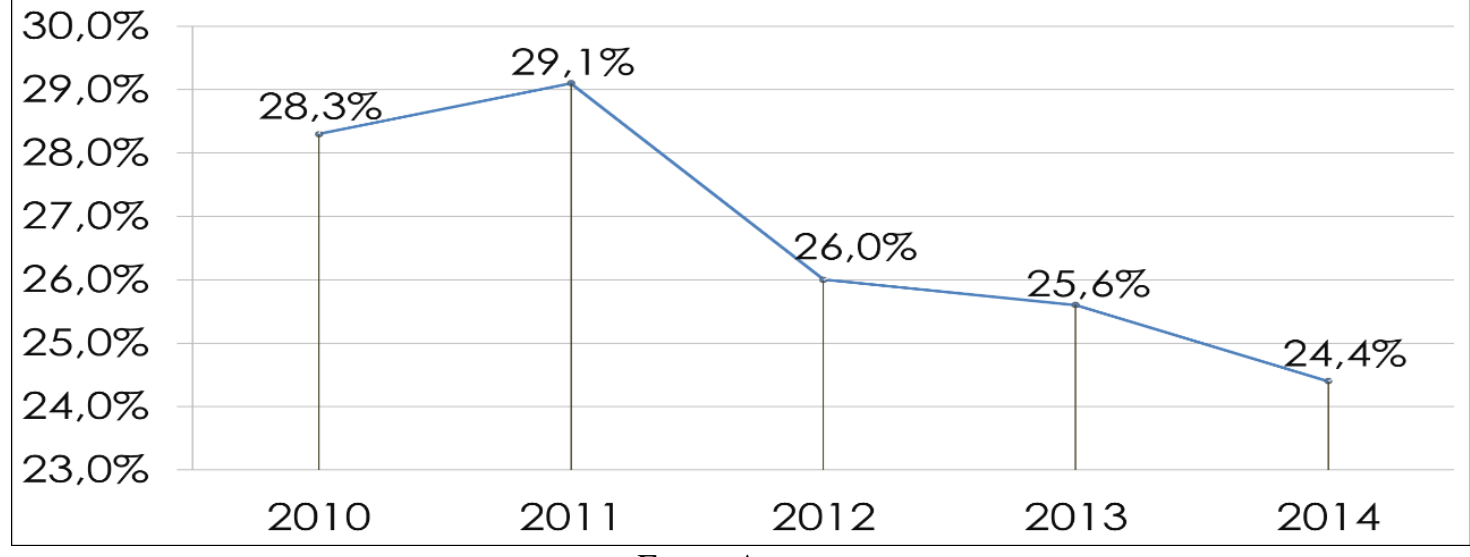

Fonte: Autores 
Tabela 1 - Distribuição das ICSAP por grupos de causas, quanto à números de internações e custos financeiros.

\begin{tabular}{l|c|c}
\multicolumn{1}{c}{ Grupos de Causas de ICSAP } & $\begin{array}{c}\mathbf{N}^{\circ} \text { de } \\
\text { intern. (\%) }\end{array}$ & Custo (\%) \\
\hline $\begin{array}{l}\text { Gastroenterites Infecciosas e } \\
\text { complicações }\end{array}$ & 33,03 & 2,38 \\
\hline Pneumonias bacterianas & 19,31 & 4,74 \\
\hline Infecção nos Rins/Trato Urinário & 9,05 & 1,89 \\
\hline Asma & 7,60 & 3,45 \\
\hline Hipertensão & 7,10 & 1,51 \\
\hline Diabetes mellitus & 4,41 & 3,18 \\
\hline Insuficiência Cardíaca & 3,78 & 6,62 \\
\hline Úlcera gastrointestinal & 3,20 & 4,04 \\
\hline Doenças Cerebrovasculares & 2,97 & 6,23 \\
\hline $\begin{array}{l}\text { Doença Inflamatória de } \\
\text { Órgãos pélvicos femininos }\end{array}$ & 2,57 & 3,08 \\
\hline Doenças pulmonares & 1,62 & 4,25 \\
\hline $\begin{array}{l}\text { Infecção da pele e tecido } \\
\text { subcutâneo }\end{array}$ & 1,24 & 4,07 \\
\hline $\begin{array}{l}\text { Infecções de ouvido, narize } \\
\text { garganta }\end{array}$ & 1,21 & 1,85 \\
\hline Angina & 0,83 & 32,07 \\
\hline Epilepsias & 0,66 & 2,45 \\
\hline Deficiências Nutricionais & 0,55 & 5,98 \\
\hline $\begin{array}{l}\text { Doenças preveníveis por } \\
\text { imunização e condições }\end{array}$ & 0,39 & 4,13 \\
\hline \begin{tabular}{l} 
sensíveis \\
\hline Anemia
\end{tabular} & 0,30 & 1,89 \\
\hline $\begin{array}{l}\text { Doenças relacionadas ao Pré- } \\
\text { Natal e Parto }\end{array}$ & 0,19 & 6,22 \\
\hline & 100,00 & 100,00 \\
\hline
\end{tabular}

Fonte: Autores 


\section{REFERÊNCIAS}

BRASIL. Ministério da Saúde. Portaria $\mathrm{n}^{\circ}$ 221, de 17 de abril de 2008. Define a lista brasileira de Internações por Condições Sensíveis à Atenção Primária. Diário Oficial da República Federativa do Brasil, Brasília, DF, 18 abr. 2008. Seção 1:70. Disponível em: < http://pesquisa.in.gov.br/imprensa/jsp/visualiza /index.jsp?jornal=1\&pagina=70\&data=18/04/2008> Acesso em 09 set. 2015.

BRASIL. Ministério da Saúde. Secretaria de Atenção à Saúde. Departamento de Atenção Básica. III Seminário Internacional Atenção Primária Saúde da Família: expansão com qualidade e valorização de resultados: relatório das atividades: Recife-PE, 13 a 15 de dezembro 2007. Brasília: Ministério da Saúde, 2008. Disponível em:

https://bvsms.saude.gov.br/bvs/publicacoes/III_seminario_atencao_primaria_familia_recife.pdf> Acesso em 28 set. 2015.

MENDONÇA, S. S.; ALBUQUERQUE, E. C. Perfil das internações por condições sensíveis à atenção primária em Pernambuco, 2008 a 2012. Epidemiol. Serv. Saúde, Brasília, v. 23, n. 3, set. 2014. Disponível em: $\quad<$ http://scielo.iec.pa.gov.br/scielo.php?scrip $\quad \mathrm{t}=$ sciarttext\&pid=S167949742014000300009\&lng=pt\&nrm=iso >. Acessos em: 09 set. 2015.

MOURA, B. L. A. et al. Principais causas de internação por condições sensíveis à atenção primária no Brasil: uma análise por faixa etária e região. Revista Brasileira de Saúde Materno Infantil. 2010, v. 10, p. s83-s91. Disponível em: <https://doi.org/10.1590/S1519-38292010000500008> Acesso em 06 set. 2015.

REHEM, T. C. M. S. B.; EGRY, E. Y. Internações por condições sensíveis à atenção primária no estado de São Paulo. Ciência \& Saúde Coletiva. 2011, v. 16, n. 12, p. 4755-4766. Disponível em: <https://doi.org/10.1590/S1413-81232011001300024> Acesso em 06 set. 2015. 